\title{
TEORIA SOCIAL, AGRICULTURA FAMILIAR E PLURIATIVIDADE*
}

\section{Sérgio Schneider}

\section{Introdução}

Atualmente, a discussão sobre a agricultura familiar vem ganhando legitimidade social, política e acadêmica no Brasil, passando a ser utilizada com mais freqüência nos discursos dos movimentos sociais rurais, pelos órgãos governamentais e por segmentos do pensamento acadêmico, especialmente pelos estudiosos das Ciências Sociais que se ocupam da agricultura e do mundo rural.

\footnotetext{
* Agradeço aos professores Ademir Cazella (UFSC) e Flávio Sacco dos Anjos (UFPel) pela cuidadosa e sugestiva leitura à versão preliminar deste artigo, assim como às sugestões dos pareceristas da RBCS. Indubitavelmente, as deficiências e as incorreções remanescentes são de minha responsabilidade. A realização deste trabalho contou com o auxílio da Fapergs (Auxílio Recém-Doutor) e do CNPq.

Artigo recebido em dezembro/2001.

Aprovado em maio/2002.
}

Embora tardiamente, se comparada à tradição dos estudos sobre esse tema nos países desenvolvidos, a emergência da expressão "agricultura familiar" emergiu no contexto brasileiro a partir de meados da década de 1990 . Neste período ocorreram a dois eventos que tiveram um impacto social e político muito significativo no meio rural, especialmente na região Centro-Sul. De um lado, no campo político, a adoção da expressão parece ter sido encaminhada como uma nova categoria-síntese pelos movimentos sociais do campo, capitaneados pelo sindicalismo rural ligado à Contag (Confederação Nacional dos Trabalhadores na Agricultura). Em meados dos anos de 1990, assistiu-se a uma verdadeira efervescência desses movimentos, que produziram inclusive formas de manifestação política que perduram até hoje, como é o caso dos eventos anuais em torno do "Grito da Terra". Diante dos desafios que o sindicalismo rural enfrentava nesta época - 
impactos da abertura comercial, falta de crédito agrícola e queda dos preços dos principais produtos agrícolas de exportação -, a incorporação e a afirmação da noção de agricultura familiar mostrou-se capaz de oferecer guarida a um conjunto de categorias sociais, como, por exemplo, assentados, arrendatários, parceiros, integrados à agroindústrias, entre outros, que não mais podiam ser confortavelmente identificados com as noções de pequenos produtores ou, simplesmente, de trabalhadores rurais.

De outro lado, a afirmação da agricultura familiar no cenário social e político brasileiro está relacionada à legitimação que o Estado lhe emprestou ao criar, em 1996, o Pronaf (Programa Nacional de Fortalecimento da Agricultura Familiar). Esse programa, formulado como resposta às pressões do movimento sindical rural desde o início dos anos de 1990, nasceu com a finalidade de prover crédito agrícola e apoio institucional às categorias de pequenos produtores rurais que vinham sendo alijados das políticas públicas ao longo da década de 1980 e encontravam sérias dificuldades de se manter na atividade. A partir do surgimento do Pronaf, o sindicalismo rural brasileiro, sobretudo aquele localizado nas regiões Sul e Nordeste, passou a reforçar a defesa de propostas que vislumbrassem o compromisso cada vez mais sólido do Estado com uma categoria social considerada específica e que necessitava de politicas públicas diferenciadas (juros menores, apoio institucional etc).

Além desses dois elementos, pode-se destacar um terceiro, que diz respeito à reorientação dos debates acadêmicos sobre a ruralidade. Surpreendentemente, a partir da segunda metade da década de 1990 assistiu-se a uma relativa retomada dos estudos agrários e rurais no Brasil que até então suscitara pouco interesse dos pesquisadores. Voltou-se a falar não apenas da agricultura e da produção agrícola, mas também do rural lato sensu. Esse novo cenário permitiu que os estudiosos ampliassem seu escopo temático para além das discussões acerca dos impasses e das possibilidades da reforma agrária e dos assentamentos, das questões relacionadas aos impactos do progresso tecnológico ou das migrações. Verifica-se, assim, a afirmação da temática ambiental e da sustentabilidade e assiste-se ao crescente interesse dos estudiosos por novos temas, como a agricultura familiar, a conformação dos mercados de trabalho e a dinâmica ocupacional da população rural.

Esse conjunto de novas temáticas, que passaram a ser objeto de pesquisas, ensejaram várias mudanças, que vão desde o estímulo ao interesse individual até reorientações de cunho teórico e epistemológico por parte de alguns investigadores. Contudo, a alteração de mais longo alcance, ainda não totalmente sedimentada nos meios sociopolíticos e no âmbito intelectual como um todo, talvez esteja relacionada à insistente afirmação de que não se pode mais confundir ou interpretar como sinônimos o espaço rural e as atividades produtivas ali desempenhadas. Embora isso não seja inteiramente novo, recentemente passou a ganhar projeção e reconhecimento no Brasil o argumento de que a agricultura como atividade produtiva não deixou de integrar o mundo rural, mas, em algumas regiões, observa-se a diminuição de sua importância no que concerne à geração de emprego e à ocupação.

Sem desconhecer que a agricultura ocupa um lugar de destaque no espaço rural, cuja importância varia segundo as regiões e os ecossistemas naturais, não se pode, contudo, imaginar que ela própria não tenha sido modificada no período recente. Em contextos internacionais, a dinâmica da própria agricultura no espaço rural vem sendo condicionada e determinada por outras atividades, passando a ser cada vez mais percebida como uma das dimensões estabelecidas entre a sociedade e o espaço ou entre o homem e a natureza. Talvez o exemplo emblemático dessa mudança estrutural seja a emergência e a expansão das unidades familiares pluriativas, pois não raramente uma parte dos membros das famílias residentes no meio rural passa a se dedicar a atividades não-agrícolas, praticadas dentro ou fora das propriedades. Essa forma de organização do trabalho familiar vem sendo denominada pluriatividade e refere-se a situações sociais em que os indivíduos que compõem uma família com domicílio rural passam a se dedicar ao exercício de um conjunto variado de atividades econômicas e produtivas, não necessariamente li- 
gadas à agricultura ou ao cultivo da terra, e cada vez menos executadas dentro da unidade de produção. Ao contrário do que se poderia supor, esta não é uma realidade confinada ao espaço rural de países ricos e desenvolvidos.

Este artigo insere-se no contexto da renovação temática e teórica assim delineado. Seu objetivo é o de contribuir no debate sobre a agricultura familiar no Brasil em situações de pluriatividade, o que implica apresentar um referencial de análise que permita entendê-la como uma estratégia de reprodução social e econômica das famílias rurais. Na primeira seção, discute-se a origem e a evolução do debate sobre a pluriatividade, em um contexto eminentemente relacionado à realidade dos países desenvolvidos. Na segunda, procura-se situar as análises sobre a pluriatividade no âmbito das tradições teóricas clássicas dos estudos agrários, mostrando como esse fenômeno já fora objeto de preocupação de autores como Chayanov e Kautsky. Na terceira, analisa-se a pluriatividade no âmbito das principais abordagens analíticas contemporâneas e indica-se o referencial teórico julgado adequado ao seu estudo. Apontamse o conceito de mercantilização de Marsden e a idéia de estratégias familiares de Fuller como conceitos úteis ao estudo da pluriatividade em situações de agricultura familiar. Na quarta seção, discute-se o problema central deste artigo a relação entre agricultura familiar e pluriatividade. Nesse sentido, é necessário definir o que se entende por agricultura familiar para, somente então, indicar as mudanças que ocorrem quando os membros da família optam por combinar a atividade agrícola com outras atividades. $\mathrm{Na}$ quinta seção, é indicada a forma de operacionalização ou a metodologia para o estudo do fenômeno da pluriatividade quando se está na presença de unidades familiares. Aqui a proposta é separar, heuristicamente, a família rural em unidade doméstica e unidade de produção, o que permite estudar a pluriatividade não apenas em relação à alocação da força de trabalho, mas também aos aspectos de gênero e hierarquia familiar, assim como as variáveis demográficas e simbólicas.

\section{Pluriatividade: a ubiqüidade de uma noção analítica}

Até meados da década de 1980, os termos part-time farming (agricultura em tempo-parcial) e pluriactivité (pluriatividade) eram utilizados quase sempre como sinônimos pelos cientistas sociais. Até então, aceitava-se que a única diferença entre ambos estava relacionada ao fato de que o primeiro termo era de uso corrente entre os analistas de língua inglesa e o segundo, mais ligado à tradição acadêmica francesa. No entanto, mais do que meras diferenças etimológicas (que em certa medida expressam a dificuldade do diálogo intelectual entre essas duas tradições), uma leitura atenta dos trabalhos que utilizam essas noções indica que elas incorporam diferentes interpretações de um fenômeno social que começou a se generalizar ainda na década de 1970, correspondente à diversificação crescente das fontes de renda e da inserção profissional dos indivíduos pertencentes a uma mesma família de agricultores.

Nos anos mais recentes, as diferenças semânticas e até mesmo as concepções teóricas acerca das noções mencionadas se alteraram significativamente na literatura internacional, podendo-se, inclusive, perceber a necessidade de consenso em torno da noção de pluriatividade. No Brasil, malgrado alguns esforços, o debate sobre a pluriatividade ainda é embrionário. Embora alguns cientistas sociais tenham despertado para a relevância do tema e orientado sua pesquisa nessa direção, o que inclusive já se reflete no espaço que a temática vem ganhando em reuniões científicas, de maneira geral a pluriatividade ainda continua a ser tratada como uma curiosidade ou um fenômeno social inteiramente específico. Embora escassos, entre os resultados de pesquisas e publicações pioneiras no Brasil pode-se citar os trabalhos de Anjos (1995), Carneiro (1996a), Neves $(1995,1997)$ e Schneider (1994, 1999a). Mais recentemente, contudo, especialmente a partir de meados da década de 1990, José Graziano da Silva, alertado inicialmente pelo surpreendente desempenho do emprego não-agrícola na PNAD (Pesquisa Nacional por Amostra de Domicílios) de 1992, vem coordenando um projeto cujo obje- 
tivo consiste em analisar o que denominou de "novo rural brasileiro", em alusão à emergência expressiva das atividades rurais não-agrícolas e da pluriatividade no meio rural brasileiro (Graziano, 1999; Campanhola e Graziano da Silva, 2000). Primeiramente restrito ao Estado de São Paulo, o projeto (chamado sugestivamente de "Projeto Rurbano") assumiu proporções nacionais, englobando análises em diversos Estados. Pode-se afirmar que o mérito da inclusão desse tema na agenda de pesquisas dos cientistas sociais brasileiros se deve ao esforço de Graziano e de sua equipe.

Em razão de esse campo de análise ser ainda recente nos estudos brasileiros, considera-se oportuno e necessário a recuperação da trajetória do debate sobre a origem e o desenvolvimento desses termos na literatura internacional. Essa revisão, já iniciada em outras oportunidades (Schneider, 1994), orienta-se pela retomada do itinerário histórico de termos, noções e conceitos para, depois, fixar-se no debate teórico e analítico, baseando-se nas pistas apontadas por outros especialistas como Fuller (1984, 1990), Marsden (1990) e Arkleton (1992) e, no Brasil, por Carneiro (1996a, 1998), Kageyama (1998) e Anjos (2001).

A principal controvérsia em relação ao termo part-time farming refere-se à utilização do tempo de trabalho na propriedade por parte do indivíduo ou da família, ao passo que a noção pluriactivité (pluriatividade) refere-se à combinação de uma ou mais formas de renda ou inserção profissional dos membros de uma mesma família. Em ambos os casos, há que se estabelecer, necessariamente, um contraponto. No primeiro, a noção de full-time farming (agricultura em tempo-integral), utilizandose, como critério de diferenciação, um determinado, embora arbitrário, corte de tempo de trabalho. No segundo, a noção de monoactivité (monoatividade), que se refere à forma de desempenho de uma atividade, o que, exatamente por ser "mono", traz implícita a idéia de que o indivíduo ou a família ocupa a integralidade de seu tempo naquela atividade. Cada uma dessas noções tem uma trajetória analítica particular. Em essência, a agricultura "monoativa" ou em "tempo integral" são semelhantes e encerram o mesmo conteúdo, mas seus opostos diferem substancialmente.
Segundo a revisão empreendida por Fuller (1984), o termo part-time farming foi criado por Rozman (apud Fuller, 1984, p. 190) para diferenciar os agricultores que produziam apenas para subsistência daqueles que se ocupavam plenamente com a produção para a venda. De acordo com sua periodização, pode-se traçar uma linha divisória entre os trabalhos anteriores e posteriores ao ano de 1975 (p. 206). Antes, os estudos enfatizavam a viabilidade econômica e o caráter transitório e instável da produção em tempo-parcial. Depois, os trabalhos adquiriram estatuto sociológico, iniciando uma fase de pesquisas marcadas pelo "enigma" em torno de conceitos e unidades de análise pertinentes ao estudo da agricultura de tempo-parcial.

Esse critério é reconhecido em outros trabalhos de revisão, como o artigo de Buttel e Larson (1982), onde consideram que até a década de 1970 o debate sobre a agricultura em tempo-parcial foi intermitente e fragmentado. Fuller sugeriu que o termo agricultura em tempo-parcial fosse substituído por multiple job holding farm bousebold (unidade agrícola familiar de trabalho múltiplo, representado pela sigla $\mathrm{MJHFH}$ ), o que permitiria reorientar a unidade de análise baseada exclusivamente no tempo de trabalho da unidade familiar. Assim, os estudos sobre as unidades agrícolas familiares de trabalhos múltiplos incorporariam três características fundamentais das famílias: composição demográfica, processo de tomada de decisão e vontades e interesses dos indivíduos, considerando-se suas situações locais e históricas (Fuller, 1984, p. 210).

Em trabalho mais recente, Fuller (1990) indica que o deslocamento de uma noção para outra não deve ser entendido apenas em face dos limites analíticos que a noção agricultura em tempoparcial impõe aos estudos empíricos (sobretudo em razão da confusão criada entre os conceitos de ocupação do produtor e da "função produtiva" da propriedade), mas também como uma decorrência dos novos desafios impostos nos anos mais recentes às próprias Ciências Sociais, particularmente a Sociologia. Esses desafios indicam, inclusive, a emergência de novos aportes teóricos para o estudo do meio rural e das transformações agrá- 
rias na década de 1980, como foi o caso da afirmação da Sociologia da Agricultura nos Estados Unidos (Buttel e Newby, 1980; Buttel, Larson e Gillespe, 1990) e da Economia Política na Europa (Marsden, 1992; Marsden, Munton e Ward, 1992 e Van der Ploeg, 1993).

Em outro trabalho, posterior, refletindo sobre o debate da década de 1980, a diferença entre agricultura em tempo-parcial e pluriatividade é apresentada de forma clara e objetiva por Fuller e Brun (1988), conforme as seguintes definições:

Nesse contexto, o termo agricultura em tempo-parcial foi substituído por unidade agrícola familiar de trabalho múltiplo que, por sua vez, foi substituído pela noção de pluriatividade, numa referência analítica à diversificação das atividades e das fontes de renda das unidades familiares agrícolas. Para Fuller, essa mudança implicou a ampliação dos objetos de pesquisa das Ciências Sociais para temas como a ligação da agricultura com o sistema agroalimentar, as relações dos agricultores com o mercado de trabalho e os aspectos intrafamiliares decorrentes do novo padrão de relações sociais e econômicas entre homens e mulheres (1990, p. 362).

Ainda segundo Fuller, há três os fatores que contribuíram para o reconhecimento acadêmico e social do conceito de pluriatividade na década de 1980. O primeiro, de ordem conceitual, refere-se ao uso impreciso da noção de agricultura em tempo-parcial, que dificultava analiticamente a separação entre o trabalho do operador principal (chefe da propriedade) e a função produtiva da propriedade. Em muitas propriedades, o tra-

\section{Part-time farming (agricultura em tempo-parcial)}

"[...] o termo part-time farming, no senso comum, até muito recentemente, tinha mais confundido do que clarificado a questão. O termo dificulta a distinção entre a unidade produtiva como uma entidade física (um espaço) e os ocupantes dessa unidade (a família ou a unidade doméstica). Estes podem fazer a gestão dessa unidade de diferentes maneiras, inclusive combinando as tarefas agrícolas com outras atividades [...]. Os termos part-time farm, parttime farmer e part-time farming têm sido utilizados de forma intercambiável, o que contribui para o surgimento de noções errôneas ou pressupostos equivocados associados a esse fenômeno. É possível dizer que uma part farm é uma unidade produtiva que oferece, ou onde é alocado, menos do que um ano completo de trabalho. $\mathrm{O}$ conceito de part-time farming pode ser utilizado, de forma mais precisa, para definir situações onde, devido ao tamanho físico ou a uma opção de gestão, a unidade produtiva é cultivada pelo investimento de menos do que um ano completo de trabalho" (Fuller e Brun, 1988, p. 150, grifos no original).

\section{Pluriactivité ou pluriactivity (pluriatividade)}

"[...] o termo procura focalizar as diferentes atividades e interesses dos indivíduos e das famílias que vivem na unidade produtiva. Preocupa-se tanto com a reprodução social e a participação no mercado de trabalho rural, como com a terra e as questões agrícolas. A pluriatividade implica uma forma de gestão do trabalho doméstico que sempre inclui o trabalho agrícola, o que não quer dizer que esta atividade seja exclusiva ou mesmo a mais importante. Outras atividades podem ser assumidas com o objetivo de sustentar ou de dar suporte à unidade doméstica, ou ainda serem motivadas por considerações não relacionadas à agricultura. A pluriatividade permite-nos questionar o pressuposto de que a full-time farming seja tanto a norma, e, portanto, algo positivo, quanto um estado temporário, ou um mal necessário, no desenvolvimento econômico das unidades produtivas, das famílias ou das áreas rurais. Esse conceito, entretanto, no plano ideal, não é facilmente mensurável por estatísticas oficiais disponíveis" (idem ibidem). 
balho externo não tinha, de fato, uma relação com a redução das atividades produtivas agrícolas. ${ }^{1}$ O segundo, diz respeito ao "deslocamento etimológico" decisivo para a afirmação desse fenômeno social como objeto de investigação acadêmica, o que ocorreu no âmbito do Arkleton Trust Project - iniciativa de pesquisadores de países ligados à então Comunidade Econômica Européia (CEE, atualmente União Européia) para estudar em profundidade as unidades familiares rurais que combinavam a agricultura com outras atividades. Essa pesquisa representou, inegavelmente, um marco no estudo da pluriatividade, pois a partir dela passou-se a utilizar a unidade doméstica (farm bousebold) como unidade de análise, e não mais o chefe da propriedade ou o tempo de trabalho gasto em atividades não-agrícolas. ${ }^{2}$ Finalmente, o terceiro fator foram os debates em torno da reforma da PAC (Política Agrícola Comum), iniciados no final da década de 1980 e concluídos em 1992, pois a crescente diversidade das ocupações do mundo rural não podia mais ser ignorada.

Esse processo de afirmação culminou com a adoção da noção de pluriatividade como a melhor forma de apreender o fenômeno da multiplicidade de formas de trabalho e renda das unidades agrícolas. De acordo com Fuller (1990, p. 367) e Newby (1987), o termo pluriatividade tem o mérito de incorporar tanto as características da noção de agricultura em tempo-parcial (unidades onde os moradores não utilizam todo seu tempo de trabalho nas atividades agrícolas) como as da multiple job bolding (unidades agrícolas que combinam múltiplas fontes de rendimento). A expressão tem sido "[...] bastante utilizada, porque abarca um conjunto de atividades que nem sempre são remuneradas em dinheiro (cash), mas com pagamentos em espécie, por meio da permuta de trabalho e outros arranjos informais" (Fuller, idem). Com essa definição, os estudiosos não apenas têm conseguido abarcar os diferentes contextos onde o fenômeno se manifesta, inclusive os pequenos produtores não integrados aos diversos mercados, os grupos identificados com o campesinato, como também examinar as relações entre o trabalho formal e informal.
Quanto ao estatuto teórico e analítico, as críticas são variadas e dirigem-se principalmente ao fato de que a noção de pluriatividade se refere sobretudo a um conjunto heterogêneo e diversificado de situações, que varia de acordo com o espaço e o contexto histórico, em que os membros de famílias de agricultores buscam atividades nãoagrícolas como ocupação (independentemente de ser uma renda principal ou complementar) e acesso a um maior nível de renda. Nesse sentido, segundo Carneiro (1996a, p. 96), corre-se o risco de atribuir "[...] a qualidade de sujeito a um conjunto de práticas cuja heterogeneidade impede que se possa delimitar criteriosamente o verdadeiro campo de estudo".

Na França, o livro organizado pela Association des Ruralistes Françaises (ARF, 1984) expressa essa disputa teórica em relação ao conteúdo analítico do termo pluriatividade. Segundo os historiadores, especialmente aqueles que estudam a chamada "proto-industrialização" (Garrier e Hubscher, 1988), as atividades não-agrícolas sempre foram praticadas por camponeses, pois integram o próprio modo de vida das sociedades rurais que não conhecem a rígida divisão social do trabalho e do espaço que caracteriza as sociedades capitalistas contemporâneas. ${ }^{3}$ Carneiro (1996b, pp. 7-12), ao revisar esse debate, destacou que, para os historiadores, a pluriatividade possui um caráter estrutural que perpassa diferentes períodos históricos e situações socioeconômicas. Por meio de um olhar disciplinar, eles percebem a pluriatividade pelos "rendimentos exteriores à unidade de produção familiar", e o termo é identificado como um fenômeno pré-moderno, pois o campesinato sempre recorreu à combinação de diversas fontes de renda e de trabalho. Mas, se a pluriatividade for compreendida como um fenômeno contrário às situações em que as pessoas se ocupam exclusivamente com uma única atividade ("monoatividade"), o caso dos "agricultores profissionais e modernos a duas unidade de trabalho homem" (UTH - unidade de medida do trabalho de um homem ao ano, considerando 300 dias de atividade), ela representa uma situação recente, típica do período pós-produtivista da década de 1970. 
Essas divergências tornam o assunto polêmico, mas não impede que a expressão seja utilizada para descrever o processo de diversificação do uso da força de trabalho que ocorre dentro e fora da propriedade, nem que aponte o surgimento de um conjunto de novas atividades no meio rural. Nesses termos, há consenso em torno de uma das mais rigorosas definições de Fuller:

A pluriatividade permite reconceituar a propriedade como uma unidade de produção e reprodução, não exclusivamente baseada em atividades agrícolas. As propriedades pluriativas são unidades que alocam o trabalho em diferentes atividades, além da agricultura familiar (bomebased farming). [...] A pluriatividade permite separar a alocação do trabalho dos membros da família de suas atividades principais, assim como o trabalho efetivo das rendas. Muitas propriedades possuem mais fontes de renda do que locais de trabalho, obtendo diferentes tipos de remuneração. A pluriatividade, portanto, refere-se a uma unidade produtiva multidimensional, onde se pratica a agricultura e outras atividades, tanto dentro como fora da propriedade, pelas quais são recebidos diferentes tipos de remuneração e receitas (rendimentos, rendas em espécie e transferências) (Fuller, 1990, p. 367).

É justamente por causa dessa aparente ubiqüidade que a noção de pluriatividade vem sendo questionada por vários autores, que reivindicam "uma delimitação mais rigorosa de um campo de observação tão difuso" (Carneiro, 1996b, p. 95). Embora essas críticas sejam pertinentes, parece ser logicamente impossível a associação direta do termo com a noção de "camponês" ou "pequeno produtor" - como pretendem os historiadores franceses, que consideram os termos quase sinônimos -, tendo em vista as características históricas de cada um. Para encerrar a controvérsia, parece válida uma sugestiva recomendação de Carneiro, para quem a pluriatividade "[...] é um termo de criação recente do vocabulário técnico, do qual o campo acadêmico se apropriou. Assim, a noção só ganha sentido se for relacionada com a política agrícola que estimulou a especialização da produção e do trabalho" (1996b, p. 10). Nessa perspectiva, a pluriatividade é, de fato, uma noção ou, no máximo, uma categoria social que se refere ao fenômeno da combinação de múltiplas inserções produtivas por um indivíduo ou uma família.

\section{As formas pioneiras da pluriatividade na agricultura: o "trabalho rural acessó- rio" e as "atividades não-agrícolas com- plementares"}

Uma vez que se concorda que o fenômeno atualmente denominado pluriatividade não representa uma situação inteiramente nova no modo de funcionamento das formações sociais e econômicas agrárias e que lhe falta conteúdo teórico e conceitual, vale pena examinar como os autores de alguns estudos clássicos interpretaram essa realidade. É nos trabalhos de Kautsky e Chayanov que se encontram algumas das primeiras referências ao "trabalho rural acessório" e a "outras atividades não-agrícolas", entendidos como formas complementares de obtenção de renda e de inserção econômica de pequenos proprietários ou camponeses.

Segundo Kautsky (1980), o desenvolvimento do capitalismo na agricultura tende a uma "lenta e gradual" subordinação à indústria. ${ }^{4}$ Para ele, o processo é comandado pela dinâmica do progresso tecnológico na agricultura (especialmente devido aos efeitos da agroquímica), que acaba por transformá-la em um ramo da indústria, completando-se, assim, uma longa evolução que resulta na afirmação da superioridade técnica da grande propriedade sobre as pequenas (ou unidades camponesas, como também são chamadas). No entanto, Kautsky afirma que o processo de transformação estrutural da agricultura sob o capitalismo não elimina, necessariamente, as pequenas propriedades desde que elas desenvolvam "formas de trabalho acessório" (que podem ou não estar ligadas à agricultura) que lhes permitam manter sua reprodução social.

A permanência de pequenos proprietários estaria relacionada à própria natureza do processo de desenvolvimento capitalista na agricultura, pois não obstante a superioridade técnica e empresarial da grande exploração, o que favorece a obtenção de maior taxa de lucro pelos capitalistas, os pequenos proprietários continuariam a de- 
sempenhar o papel fundamental de fornecimento da força de trabalho para as unidades maiores. Segundo Kautsky:

[...] não devemos pensar que a pequena propriedade territorial esteja em vias de desaparecer na sociedade moderna, ou que possa ser inteiramente substituída pela grande propriedade. A grande propriedade, por mais que rechace os camponeses livres, sempre manterá uma parte deles à sua ilharga, uma parte que ressuscita como pequenos arrendatários (1980, p. 178).

No entanto, o autor ressalta, a possibilidade de persistência das pequenas propriedades camponesas somente é admitida sob a condição de que elas venham a assumir uma função acessória e complementar à grande empresa que, por sua vez, exercerá seu pleno domínio no terreno da produção agrícola. Tal função estaria relacionada à pouca disponibilidade de terra e às dificuldades de modernização tecnológica, o que restringe sua capacidade de concorrência e reduz sua renda a níveis que obrigam essas pequenas unidades a buscar uma atividade complementar ou, então, a abandonar definitivamente o campo. De acordo com Kautsky (1980, pp. 194-206), existem três tipos de ocupação acessória que podem exercer esse papel:

a) Trabalho agrícola assalariado, mais conhecido como trabalho temporário, exercido nas grande propriedades em épocas de maior demanda por mão-de-obra, como nas colheitas.

b) Ocupação dos camponeses em indústrias a domicílio, o que, em geral, ocorre em regiões de pouca aptidão agrícola para consolidar uma agricultura competitiva, caso de várias áreas na Alemanha e no restante da Europa por ocasião de seus estudos. Apesar de ser menos eficiente do que a grande indústria urbana, para Kautsky a indústria a domicílio rural desfrutaria da vantagem de se apoiar na agricultura, o que lhe permite rebaixar os custos de produção, especialmente com a remuneração da força de trabalho. c) Fundação de indústrias no campo, que progride em função do avanço das comunicações (canais, estradas de ferro, telégrafos), o que também ocasiona a necessidade de trabalhos complementares para as famílias de pequenos proprietários (idem, p. 205)

Assim, afirma Kautsky, "[...] estas três espécies de trabalho acessório ao alcance dos pequenos camponeses não se excluem de modo algum. Podem existir simultaneamente, e, freqüentemente, coexistem" (idem, p. 206). Portanto, pode-se dizer que a questão das atividades rurais não-agrícolas (ainda que não explicitamente nesses mesmos termos) aparece na obra de Kautsky não apenas como uma forma de reafirmação de seu argumento central, em favor da superioridade técnica da grande propriedade e do inequívoco processo de industrialização da agricultura (tornandoa um apêndice da indústria), mas também como uma divergência a Lênin, Engels e ao próprio Marx, já que o autor tem uma visão radicalmente distinta a respeito dos desígnios da estratificação social e econômica decorrente do processo de penetração do capitalismo no campo.

Fora do escopo do marxismo, outro autor pioneiro a destacar a importância das "atividades rurais não-agrícolas" foi Alexander V. Chayanov (1974). Para se compreender a explicação desse autor sobre as razões que levaram os camponeses russos a buscar atividades complementares no meio rural é necessário situar sua tese em um quadro analítico mais amplo, qual seja, a "teoria da unidade econômica camponesa (UEC)", cujo objetivo é analisar os aspectos organizacionais da unidade econômica camponesa a partir de seus "elementos morfológicos estáticos". ${ }^{5}$ No centro dessa formulação está "[...] a hipótese de um balanço subjetivo entre trabalho e consumo para analisar os processos de continuidade da unidade econômica camponesa e para estabelecer a natureza da motivação da atividade econômica da família" (Chayanov, 1974, p. 38). Essa hipótese sustenta-se na idéia de que, na agricultura camponesa, a família é o elemento-chave para explicar o processo de tomada de decisão por parte dos indivíduos no que se refere à produção, à aloca- 
ção da força de trabalho, à utilização dos equipamentos e ao investimento. Assim, a compreensão do funcionamento das unidades econômicas camponesas pressupõe a análise do modo pelo qual as famílias solucionam seus problemas com vistas à manutenção de uma situação de equilíbrio, vital para garantir sua reprodução social. A avaliação subjetiva da família, portanto, é decisiva para definir o "grau de auto-exploração" das unidades econômicas camponesas no que se refere ao volume da atividade agrícola, à intensidade do trabalho e ao destino da produção. Tal avaliação tem como referência a manutenção do balanço entre trabalho e consumo.

Embora a idéia de equilíbrio entre trabalho e consumo seja visivelmente fundadora do esquema analítico de Chayanov, sua principal contribuição reside na identificação de elementos próprios ao comportamento da família, que é quem regula e operacionaliza a unidade de produção agrícola. Segundo Chayanov, deve-se considerar a família sob três aspectos centrais. Primeiro, em seu ciclo demográfico completo, o que implica relacionar a variação da utilização dos fatores produtivos (terra, trabalho e meios de produção) ao seu processo de diferenciação interna. Segundo, deve-se buscar entender o "caráter teleológico" do comportamento das ações familiares, que organiza o funcionamento dos "mecanismos internos de equilíbrio" (Chayanov, 1974, p. 287). Essa racionalidade orienta-se na direção da "utilização ótima de fatores" (terra, capital e força de trabalho), estabelecida a partir do tamanho da família e seu grau de auto-exploração em relação às condições objetivas dos meios de produção (idem, p. 99). Terceiro, a composição e a união entre a unidade doméstica (ou de consumo) e a unidade de produção, o que faz com que a família funcione como um todo, especialmente no que se refere à gestão de sua rendas (idem, pp. 110-112).

O modelo analítico de Chayanov é crucial para se compreender o significado das atividades rurais não-agrícolas, às quais o autor se refere de modo recorrente. Nesse sentido, assume também relevância o conceito de estratégia que, para o autor, funciona como um conjunto de ações conscientes e planejadas que a família se utiliza para alcançar seus objetivos. Esse conceito, na verdade, baseia-se na "relação ótima de fatores de produção", que consiste na adequação das necessidades familiares à conveniência técnica em um determinado sistema de produção (idem, p. 98).

Desse modo, em situações em que a família não dispõe de uma quantidade suficiente de terra para suas necessidades, ou quando "sobram braços" para trabalhar, ela tende a buscar em "atividades artesanais e comerciais ou em outras atividades não-agrícolas" uma forma de ocupar a força de trabalho para garantir o equilíbrio entre trabalho e consumo (idem, p. 101). Essas estratégias não são derivadas de um cálculo aritmético ou de uma racionalidade guiada pelo lucro ou pela acumulação, mas tão-somente orientadas pelas necessidades, que variam ao longo do ciclo demográfico familiar. Assim, Chayanov demonstra que o recurso a atividades não-agrícolas é determinado, primeiramente, pela variação neste ciclo. Nas fases em que a família possui filhos pequenos ou quando resta apenas o casal de velhos (e, às vezes, um filho que se ocupa deles), a demanda por trabalhos não-agrícolas é menor vis-à-vis as situações em que a família amplia sua capacidade de trabalho ante a maior aptidão dos filhos. Nesse caso, quando há subocupação da força de trabalho, o recurso às atividades não-agrícolas tornase uma alternativa.

No entanto, apesar de a busca por atividades não-agrícolas variar segundo o ciclo demográfico, isso não quer dizer, segundo Chayanov, que o tamanho da família seja o único critério que orienta a divisão familiar do trabalho entre atividades agrícolas e não-agrícolas. É preciso também levar em conta os elementos técnicos que influenciam a produção, porque a adoção de meios de produção mais eficazes poderia suprir a falta de mãode-obra. A divisão do trabalho familiar também se orienta "pelas condições econômicas gerais que se dão localmente" (idem, p. 116). Assim,

[...] a suposição de que a procura de capital e, sobretudo, de terra induz a família camponesa a orientar parte considerável de sua mão-de-obra para atividades não-agrícolas está perfeitamente correta na maioria dos casos. O êxodo para os ofícios não-agrícolas acontece, com efeito, de 
modo particular nas zonas de grande densidade demográfica (idem, p. 118).

Essa afirmação, contudo, segundo o próprio Chayanov, exige o estabelecimento de dois condicionantes:

a) O fato de que o desenvolvimento de atividades não-agrícolas está relacionado à irregularidade da distribuição do tempo de trabalho na agricultura, pois em determinadas estações, como no inverno (no caso russo), a inatividade pode ser quase total.

b) Em muitas situações não é a falta de meios de produção o que origina os ganhos com atividades não-agrícolas, mas uma situação de mercado mais favorável para esse tipo de trabalho, em termos de remuneração, em comparação com aquela derivada da venda de produtos agrícolas (idem, p. 118).

Para Chayanov, o recurso às atividades nãoagrícolas é uma estratégia de alocação da força de trabalho familiar ante os condicionantes da unidade produtiva agrícola e expressa, acima de tudo, a racionalidade que a família imprime às suas atitudes para manter o equilíbrio entre trabalho e consumo e garantir, assim, sua reprodução.

Trata-se de atividades artesanais e comerciais que fornecem uma remuneração muito mais elevada por unidade de trabalho. Com sua ajuda pode-se obter ganhos maiores com menos esforço, e a família prefere ajustar o equilíbrio básico entre consumo e desgaste da força de trabalho principalmente por meio da ocupação em artesanato e comércio [...]. Em outras palavras, podemos assegurar teoricamente que a divisão do trabalho na família camponesa entre atividades agrícolas e nãoagrícolas (artesanato e comércio) é levada a cabo pela comparação da situação de mercado desses ramos da economia nacional" (idem, p. 120).

Embora muitas vezes as atividades não-agrícolas sejam exercidas fora da propriedade, ainda segundo as formulações de Chayanov, isso não comprometeria o caráter indivisível dos rendimentos familiares. Trata-se de um "sistema único de equilíbrio básico" que faz com que haja uma interdependência entre os ganhos totais da família (idem, p. 112).

\section{A teoria social contemporânea e o lugar da pluriatividade: a contribuição da so- ciologia da agricultura}

Uma revisão cuidadosa da literatura internacional que procura situar o debate sobre a pluriatividade no contexto das reflexões sobre a agricultura familiar mostra que os avanços teóricos e metodológicos mais significativos sobre esses temas se encontram na corrente do pensamento social contemporânea denominada "Sociologia da Agricultura" (Buttel, Larson e Gillespie Jr., 1990). Trata-se de uma abordagem relativamente recente na área dos estudos rurais e agrários, cuja definição teórico-metodológica é eclética e pluralista, variando de enfoques neomarxistas a neoweberianos, e alicerçada por uma orientação genérica que os autores denominam "perspectiva crítica" (Schneider, 1997). Apesar da multiplicidade de enfoques, há consenso entre os autores ligados a essa área da sociologia de que a agricultura familiar encerra uma diversidade de situações e possui múltiplas estratégias de reprodução social.

A principal divergência entre os expoentes dessa vertente teórica evidencia-se nas suas interpretações acerca do papel e da posição dos agricultores diante das transformações estruturais da agricultura sob o regime capitalista. De um lado, há os que abordam as mudanças sociais, econômicas e espaciais da agricultura e do mundo rural a partir da internacionalização do sistema agroalimentar (agri-food-system), apontando a homogeneização dos mercados de trabalho rural e urbano e o aumento da hegemonia do capital financeiro em escala global como suas características principais. Em contrapartida, uma segunda vertente focaliza o processo de reestruturação da agricultura a partir do estudo da agricultura familiar e das estratégias que as famílias rurais adotam, entre as quais a pluriatividade. ${ }^{7}$

Como no espaço deste artigo não será possível apreciar todas as perspectivas analíticas que integram a Sociologia da Agricultura, optou-se por apresentar a contribuição teórica mais ade- 
quada e que melhor se ajusta à reflexão sobre a agricultura familiar em situações de pluriatividade. Terry Marsden e Anthony Fuller estão entre os autores do pensamento social contemporâneo que mais têm contribuído para constituição de um arcabouço analítico para discussão da pluriatividade e temas correlacionados.

Segundo Marsden, é necessário compatibilizar as análises gerais sobre as transformações estruturais (encapsulada na utilização recorrente da idéia de "reestruturação capitalista") com as transformações particulares que afetam a agricultura familiar. Ou seja, trata-se de fazer uma analogia entre o processo de reestruturação da agricultura e o papel desempenhado pela pluriatividade. Nesse sentido, o autor insiste na retomada de análises sobre o funcionamento dos processos produtivos no espaço rural, que seriam o locus privilegiado para a observação das transformações das unidades familiares (Marsden, Whatmore, Munton e Little, 1986). Para isso, Marsden propõe a utilização de conceitos fundamentais do debate sobre a mercantilização social e econômica (commoditization debate), discussão lançada na segunda metade dos anos de 1980 pelos estudiosos da escola holandesa de Wageningen (em particular Norman Long e Jan Douwe Van der Ploeg), cujo objetivo era propor uma alternativa analítica à utilização da noção de produção simples de mercadorias para explicar a persistência da agricultura familiar. Marsden resgata o conceito de "mercantilização do espaço agrário" acrescentando-lhe a idéia de que se trata de um processo de desenvolvimento desigual, que aos poucos integra certos tipos de agricultores e regiões produtivas enquanto outros vão sendo excluídos e marginalizados (Marsden, 1991).

A partir desse marco teórico geral, Marsden passa a analisar o processo de reestruturação capitalista da agricultura que eclodiu com as mudanças radicais decorrentes da crise do modelo fordista de produção e consumo de massa vigente nos países desenvolvidos entre o pós-Guerra e meados da década de 1970 (Marsden et al., 1986). De acordo com o autor, ao contrário do que sugere parte da literatura internacional, os processos de flexibilização e de descentralização industrial e, sobretudo, de informalização das relações de trabalho não necessitam de um "novo modelo" societário, mas, um recuo do próprio fordismo (1992, p. 210). As características mais salientes desse recuo poderiam ser percebidas por meio das mudanças no mercado de trabalho, da emergência de novas formas de regulação das relações de trabalho e das novas tecnologias e formas de gestão dos processos produtivos.

Em vez de construir novos modelos analíticos em substituição ao fordismo, Marsden afirma que os cientistas sociais deveriam se preocupar em desenvolver análises capazes de incorporar a dimensão local, nacional e internacional dos espaços, dando ênfase à articulação social e política dessas esferas. Essa perspectiva de análise desdobra-se em dois vetores. Primeiro, segundo o autor, as novas formas de organização econômica devem ser entendidas a partir de suas especificidades e das configurações particulares que assumem as novas formas de regulação da ação social. Segundo, deve-se analisar as diferentes trajetórias do capitalismo recombinando-as com base nas diferenças socioespaciais (Marsden, 1989, Marsden et al., 1987).

Desde o início da década de 1990, de acordo com Marsden, estão em curso mudanças na política agrícola dos países desenvolvidos que estimulam a diversificação e o aumento da produção, o que pode ser entendido como um indício de que o próprio Estado cria mecanismos novos de regulação social e econômica dos espaços rurais. Essas iniciativas vêm de encontro ao recuo do padrão fordista de produção em massa na agricultura ("pós-produtivismo") e contribuem para a disseminação de novas formas de reprodução da força de trabalho no meio rural, sendo a pluriatividade a expressão mais eloqüente desse redirecionamento (1995, p. 291). ${ }^{8}$ Assim, o espaço rural, que durante o fordismo se limitara a cumprir funções produtivas agrícolas e alimentares, ganha novas atribuições, tornando-se um lugar onde se desenvolvem múltiplas atividades produtivas e ocupacionais.

Entre suas novas funções, o autor destaca o papel do consumo de bens materiais e simbólicos (por exemplo, propriedades, festas, folclore e gastronomia) e serviços (ecoturismo, atividades liga- 
das à preservação ambiental etc.), indicando que na fase pós-fordista o espaço rural não pode mais permanecer circunscrito à sua função na produção agrícola ou ao uso da terra para o cultivo de produtos alimentares e de matérias-primas. Portanto, para se compreender o meio rural é preciso ir além da perspectiva agro-alimentar, ou seja, deve-se analisar as relações de produção e consumo em uma dimensão local e global. Marsden propõe que o conceito-chave para explicar a nova configuração socioeconômica e espacial do meio rural seja a noção de commoditization (mercantilização) que, na sua opinião,

[...] representa um amplo processo social e político pelo qual os valores mercantis são construídos e atribuídos a objetos rurais e agrícolas, mas também ao artesanato e às pessoas. Ela não representa um processo único e universal que transforma apenas o trabalho na agricultura (tal como sugerido na literatura marxista sobre o desenvolvimento agrário). Trata-se, ao contrário, de um fenômeno diversamente construído, em torno do qual os processos de desenvolvimento coalescem e se generalizam (Marsden, 1995, p. 293).?

Com base nessas formulações, Marsden considera que a pluriatividade tende a se generalizar tanto em áreas de produção agrícola, onde o avanço tecnológico diminuiria a demanda de trabalho, como nas demais zonas rurais, onde o próprio Estado vem estimulando o desenvolvimento de outras atividades econômicas, como o turismo e o artesanato (Marsden e Flynn, 1993). O autor acredita que esse processo conduzirá à revalorização do espaço rural, especialmente em razão do rápido crescimento do movimento ambientalista e dos processos de descentralização industrial, que tendem a ampliar o mercado local de trabalho e, conseqüentemente, a adoção da pluriatividade nas famílias rurais.

Ao afirmar que a pluriatividade decorre, em larga medida, das transformações engendradas pelo próprio processo de reestruturação capitalista, Marsden fornece ainda pistas importantes para a análise das transformações do mercado de traba1ho. Nesse sentido, recupera a tese de Bradley (1984), segundo a qual uma das características centrais do capitalismo no período pós-fordista é o processo de segmentação do mercado de trabalho, decorrente das novas formas de organização dos processos produtivos que tem como característica principal a descentralização horizontal e a flexibilização das relações de trabalho. ${ }^{10}$ Esse processo reflete os impactos desiguais sobre o espaço rural, que passa, por meio do mercado de trabalho, a ser também integrado à dinâmica capitalista.

Desse modo, Marsden vê a pluriatividade como uma configuração, por excelência, das relações de trabalho contemporâneas, decorrente dos processos recentes de relocalização econômica. Embora o autor insista no fato de que a pluriatividade seja uma decorrência dos novos contornos sociais, econômicos e espaciais da reestruturação capitalista, também reconhece que os elementos "exógenos" (sobretudo o mercado de trabalho de atividades não-agrícolas) não são suficientes para explicar inteiramente esse fenômeno. Para se compreender os tipos de impacto que essas transformações provocam nas decisões das famílias rurais, especialmente no que se refere ao recurso à pluriatividade como estratégia de reprodução social, Marsden sugere a análise das relações sociais internas às propriedades e ao processo produtivo (1990, p. 378):

Precisamos enfatizar a contínua transformação da agricultura familiar, e não sua estagnação como uma forma de produção. O esforço de investigação precisa se deter sobre as oportunidades e as limitações com as quais a unidade familiar se vê confrontada e sobre as concessões que as famílias de agricultores constantemente se vêem forçadas a fazer em resposta às pressões internas e externas de mudança. As análises podem, então, incorporar as relações internas à unidade produtiva, principalmente no que se refere às questões geracionais e de gênero, bem como as relações estabelecidas entre a unidade produtiva e o capital externo. É este conjunto complexo de interações, desenvolvido em condições locais e históricas específicas, que deve servir de base para o estudo da natureza e da dinâmica da agricultura familiar (Munton e Marsden, 1991, p. 109).

Ou seja, Marsden propõe uma via para definir conceitualmente o que chama de unidade familiar rural, qual seja, o estudo das relações sociais engendradas pela dinâmica do processo de 
trabalho. Seu ponto de partida é o pressuposto de que as unidades familiares são compelidas a buscar novas fontes de renda fora da propriedade devido ao ingresso em um ambiente competitivo, o que impede que sobrevivam apenas e exclusivamente dos ganhos obtidos com as atividades agrícolas. Dada essa nova configuração do mercado de trabalho e da importância que assume o espaço rural como um espaço mercantilizado de bens e serviços, parte expressiva das unidades familiares agrícolas tornam-se pluriativas, garantindo, assim, condições razoáveis de sobrevivência. ${ }^{11}$

O trabalho de Fuller é também uma referência fundamental para o entendimento do conceito de pluriatividade e pode ser considerado um complemento aos estudos de Marsden, cuja perspectiva é inspirada nos fundamentos epistemológicos neomarxistas da Sociologia da Agricultura. Fuller interpreta a pluriatividade a partir dos mecanismos que as famílias estabelecem com o mercado e o ambiente externo, enfatizando que a natureza da divisão interna do trabalho exerce uma influência decisiva sobre as estratégias adotadas por elas.

Em seus primeiros trabalhos, Fuller propõe que o estudo da pluriatividade não deve ficar restrito à mensuração do tempo que o chefe da propriedade dedica às atividades agrícolas e não-agrícolas. Sugere que se tome a família e o seu ciclo de reprodução como eixo principal de análise, já que a decisão pela diversificação das atividades familiares depende também dos recursos, dos costumes e das tradições da família. Para Fuller, "[...] deve-se entender a propriedade familiar como uma unidade econômica onde a família é o principal agente das decisões" (1983, p. 7). Essa definição contempla a família como um todo, fazendo com que a noção de propriedade familiar não se circunscreva apenas ao chefe da propriedade ou aos membros que trabalham fora.

Em trabalhos mais recentes, e como consultor principal do projeto "Estruturas Agrárias e Pluriatividade das Famílias Agrícolas (1987-1990)", patrocinado pelo Arkleton Trust, ${ }^{12}$ Fuller foi um dos precursores da idéia de que se deve estudar a pluriatividade a partir da dinâmica interna da família, e de como ela reage ao jogo das instituições e dos condicionantes do mercado no sistema lo- cal (Fuller, 1987, p. 11). Para ele, a pluriatividade é um elemento de diversificação que pode se produzir tanto no interior da família como a partir do exterior, pois funciona como uma estratégia que se modifica de acordo com a dinâmica das famílias e de sua relação com a estrutura agrária (Brun e Fuller, 1991, p. 25). Entre as principais conclusões do projeto mencionado, tem-se a idéia de que a pluriatividade

[...] se reveste de diferentes formas em função das fontes de renda e da inserção da mão-de-obra e preenche diferentes funções. Todavia, a pluriatividade não pode mais ser considerada unicamente um fenômeno estrutural associado à transição e que constitui a saída para a agricultura, ou a necessidade de incrementar as rendas das pequenas propriedades, ainda que esses aspectos se mantenham importantes (Arkleton Trust, 1992, p. 19).

Assim, segundo os autores, a pluriatividade constitui-se em um traço importante da agricultura européia, e sua presença não está relacionada somente ao tamanho dos estabelecimentos ou à localização em determinadas áreas (consideradas marginalizadas). Ao contrário, constatou-se que ela não é um fenômeno efêmero, mas generalizado por toda a estrutura agrária da Europa, além de englobar uma diversidade de práticas e atividades agrícolas e não-agrícolas.

Nesse sentido, para Fuller, a pluriatividade apresenta variações muito expressivas de situações de espaço e de tempo, ainda que se possa afirmar que sua característica fundamental seja a interação entre agricultura, unidade familiar e mercado de trabalho (1990, p. 368). Do ponto de vista teórico e conceitual, isso implica a definição de três níveis de análise, que também foram utilizados no estudo de Arkleton Trust. O primeiro toma a pluriatividade como uma expressão de determinados tipos de economia regional ou local. Trata-se de sua projeção espacial, bem como de suas interações com a estrutura econômica e as condições socioculturais e políticas ali instauradas. Busca-se saber, por exemplo, quais são os fatores regionais ou locais que exercem atração e estímulo, e, em contrapartida, os restritivos ou limitadores ao desenvolvimento da pluriatividade. 
O segundo refere-se à abordagem da família como o núcleo das decisões para compreender as relações entre a agricultura e a pluriatividade. A decisão de alocação dos recursos disponíveis (capital, trabalho etc.), bem como a opção por uma determinada estratégia de investimento em atividades agrícolas ou não-agrícolas são decisivas para a compreensão das diversas formas possíveis que assume a pluriatividade. O terceiro, por sua vez, refere-se à interpretação da pluriatividade como uma expressão da dinâmica das transformações socioeconômicas estruturais dos espaços rurais. Ou seja, trata-se do enfoque histórico e comparativo entre regiões, comunidades e até países, no sentido de se averiguar os fatores que podem contribuir para explicar as distintas funções da pluriatividade, como, por exemplo, o tamanho e a composição familiar e a disponibilidade de um mercado de trabalho de atividades não-agrícolas (Brun e Fuller, 1991, pp. 26-28).

\section{A pluriatividade como característica da agricultura familiar}

Como fenômeno social e econômico presente na estrutura agrária de regiões e países, podese definir a pluriatividade como um fenômeno através do qual membros das famílias que habitam no meio rural optam pelo exercício de diferentes atividades, ou, mais rigorosamente, pelo exercício de atividades não-agrícolas, mantendo a moradia no campo e uma ligação, inclusive produtiva, com a agricultura e a vida no espaço rural. Nesse sentido, ainda que se possa afirmar que a pluriatividade seja decorrente de fatores que lhe são exógenos, como o mercado de trabalho nãoagrícola, ela pode ser definida como uma prática que depende de decisões individuais ou familiares. Interessa, pois, avaliar o significado econômico, o sentido sociocultural da consolidação da pluriatividade em famílias que residem no espaço rural e se integram em outras atividades ocupacionais, combinando-as com a atividade agrícola.

Com efeito, ao delimitar as fronteiras conceituais entre a agricultura familiar e a pluriatividade, o passo seguinte consiste em evidenciar o referencial teórico que alicerça essa definição. Cabe, por- tanto, explicitar como é entendida a agricultura familiar e por que a pluriatividade se tornou uma das estratégias de sobrevivência. Assim, a discussão teórica acerca da pluriatividade deve envolver o debate mais amplo sobre a persistência da forma familiar de trabalho e de produção no interior do capitalismo. Parte-se do pressuposto de que a dinâmica socioeconômica no meio rural faz parte da sociedade como um todo, e que, em determinadas situações históricas, ela certamente será estabelecida pelo regime capitalista. Mas essa não é uma "regra universal", e o modo pelo qual a forma familiar interage com o capitalismo pode variar e assumir feições muito particulares. Em alguns casos históricos, as formas sociais identificadas com o trabalho familiar acabaram sucumbindo e foram absorvidas pelo próprio capitalismo mas, em outros, como no caso de certas configurações da pluriatividade, a presença do trabalho familiar em unidades produtivas agrícolas pôde desenvolver relações até certo ponto estáveis e duradouras com as formas sociais e econômicas predominantes. Assim, as unidades familiares subsistem com uma relativa autonomia em relação ao capital e vão se reproduzindo nessas condições. A sua transformação vai depender de sua relação com as formas distintas e heterogêneas de estruturação social, cultural e econômica do capitalismo, em um certo espaço e contexto histórico.

Há controvérsia metodológica entre os estudiosos que, segundo Neves (1995), decorre em larga medida da capitulação dos pesquisadores ao raciocínio dualista, tipológico e ordenador dessa heterogeneidade, que vale à pena ser comentado. O que está em jogo é a definição das unidades familiares que utiliza como referencial o outro extremo de uma suposta polaridade, qual seja, a unidade ou a empresa capitalista. Às formas familiares corresponderiam características como trabalho familiar, resistência à apropriação do excedente via mercado, propriedade de meios de produção, busca de autonomia etc.; às formas capitalistas seriam definidas por assentarem-se em trabalho assalariado, apropriação de mais-valia, reprodução ampliada, racionalidade dirigida à obtenção de produtividade e rentabilidade, entre outros aspectos. Dessa classificação derivam qua- 
lificações empíricas, muitas vezes utilizadas para caracterizar os próprios produtores, como a polarização entre produtor tecnificado ou capitalizado versus os camponeses, pobres ou tradicionais. Esse tipo de raciocínio, que segundo Neves deriva de equívocos metodológicos, reduz a compreensão e a análise das formas sociais existentes no campo à mera contraposição de dois segmentos: um social, caracterizado pelas unidades familiares, e outro, econômico, consagrado à empresa capitalista.

Entretanto, acredita-se ser possível e adequado o delineamento de alguns elementos que auxiliem a elaboração de uma definição mais abrangente acerca da agricultura familiar ou da forma familiar de organizar o trabalho e a produção na atividade agrícola, e isso, com certeza, será útil para a compreensão de suas características em sociedades capitalistas. ${ }^{13} \mathrm{O}$ primeiro elemento diz respeito à forma de uso do trabalho. As unidades familiares funcionam, predominantemente, com base na utilização da força de trabalho dos membros da família que, por sua vez, podem contratar, em caráter temporário, outros trabalhadores. No entanto, a utilização de critérios de quantificação para determinar o limite a partir do qual uma unidade familiar que usa trabalho contratado deixa de ser considerada como tal constitui-se em operação heurística que, isoladamente, não é suficiente para se entender e se caracterizar sociologicamente sua natureza, ou seja, como vivem seus integrantes e por que tomam determinadas decisões. ${ }^{14}$

O segundo elemento refere-se aos obstáculos oferecidos pela natureza, que impedem uma eventual correspondência, em essência, entre a atividade produtiva agrícola e industrial. Embora notórios, os avanços científicos e tecnológicos ainda não conseguiram eliminar a "base natural" sob a qual se assenta a produção de alimentos e fibras, e muito menos subverter os processos produtivos agrícolas a ponto de suprimir a distinção, em termos de funcionamento, entre agricultura e indústria. ${ }^{15}$ De fato, malgrado argumentos contrários, um olhar atento sobre a produção agrícola é suficiente para convencer o observador de que se trata de uma atividade ainda muito dependente de fatores naturais como clima, solo, ou equilíbrio dos ecossistemas. Na agricultura, o tempo de trabalho que se gasta para produzir uma mercadoria, sobretudo nas situações em que a produção é especializada, não corresponde ao tempo de produção necessário à sua elaboração. Além disso, é cada vez mais perceptível o apelo que a produção dita "natural" exerce sobre os consumidores, forjando, inclusive, situações específicas de mercado para essas mercadorias. Portanto, as barreiras naturais continuam limitando o desenvolvimento de economias de escala na agricultura, impedindo, assim, uma total subordinação dos processos produtivos ao interesse do capital, e, por isso, operando com base em relações de trabalho não assalariadas. Não é por acaso que uma parcela majoritária da produção agroalimentar dos países capitalistas mais desenvolvidos continua nas mãos dos agricultores familiares.

O terceiro elemento pode ser extraído da teoria social. A tradição marxista sempre privilegiou o enfoque do desenvolvimento agrário como um processo macrosocial e econômico sem considerar a resistência das formas familiares e reconhecer a capacidade de adaptação e interação dessas categorias sociais no sistema dominante. É necessário ajustar esse enfoque no sentido de deslocar seu referencial holístico e nomológico para a compreensão das formas de articulação da agricultura familiar com o ambiente social e econômico em que estiver inserida. Este ambiente é constituído por um conjunto de instituições que fornece estímulos e determina os limites e as possibilidades, exercendo, assim, uma influência decisiva sobre as decisões individuais e familiares. As relações dos agricultores com o ambiente social e econômico podem ocorrer por meio do crédito, do financiamento ou de outra forma de apoio institucional - Estado ou ONGs -, e também pelo acesso a mercados de produtos (compra de insumos e venda de mercadorias, relação com a agroindústria etc.), mercado de trabalho (como a possibilidade de obter rendas em atividades não-agrícolas), acesso e informações e inovações produzidas pelo progresso tecnológico. Além disso, o ambiente social e econômico também compreende as expectativas cambiantes e as percepções que as famílias nutrem em relação ao 
seu futuro e às possibilidades de desenvolvimento do local em que vivem.

Contudo, o elemento central que patrocina a relativa estabilidade e exerce um papel regulador entre os diferentes aspectos aqui apresentados é a própria natureza familiar das unidades agrícolas, que está assentada nas relações de parentesco e de herança existentes entre seus membros. É no interior da família e do grupo doméstico que se localizam as principais razões que explicam, ao mesmo tempo, a persistência e a sobrevivência de certas unidades e a desagregação e o desaparecimento de outras. ${ }^{16}$ As decisões tomadas pela família e pelo grupo doméstico ante as condições materiais e o ambiente social e econômico são cruciais e definidoras das trajetórias e estratégias que viabilizam ou não sua sobrevivência social, econômica, cultural e moral.

Mesmo que em certos casos as unidades familiares estejam submetidas a determinados condicionantes externos como, por exemplo, o monopólio de preços ou os diferentes tipos de mercado (de trabalho, de crédito, de produtos e insumos, entre outros), o fato de estruturaremse com base na utilização da força de trabalho de seus membros permite que determinadas decisões se tornem possíveis, o que muitas vezes um agricultor muito inserido na dinâmica capitalista, contando com a contratação de assalariados, não poderia concretizar ou sofreria fortes restrições. Isso não significa concordar com a idéia de que essa especificidade do caráter familiar seja suficiente para explicar por que algumas unidades conseguem reproduzir-se ou resistir, mesmo em condições adversas.

A reprodução social, econômica, cultural e simbólica das formas familiares dependerá de um intrincado e complexo jogo pelo qual as unidades familiares se relacionam com o ambiente e o espaço em que estão inseridas. Nele os indivíduos e a família devem levar em conta o bem-estar e o progresso de sua unidade de trabalho e moradia e as possibilidades materiais de alcançar determinados objetivos. Desse modo, a reprodução não é apenas o resultado de um ato da vontade individual ou do coletivo familiar, e tampouco uma decorrência das pressões econômicas externas do sistema social. A reprodução é, acima de tudo, o resultado do processo de intermediação entre os indivíduosmembros com sua família e de ambos interagindo com o ambiente social em que estão imersos. Nesse processo cabe à família e a seus membros um papel ativo, pois suas decisões, estratégias e ações podem trazer resultados benéficos ou desfavoráveis à sua continuidade e reprodução.

Essa perspectiva permite romper com o usual reducionismo classificatório dos estudos sobre a agricultura familiar, pois nem a categoria trabalho familiar estritamente, nem a contratação ou não de assalariados, nem tampouco as relações com o mercado servem, isoladamente, como critérios para definir a natureza de uma determinada forma social. Nesse sentido, para se entender o significado da pluriatividade em situações onde predomina a agricultura familiar a partir das ferramentas conceituais disponibilizadas pela sociologia crítica, é preciso admitir que determinadas formas sociais se transformam (no sentido de que se superam), se metamorfoseiam e se reproduzem fora do escopo rígido das leis de valorização do capital. Trata-se de aceitar a hipótese de que determinadas formas sociais estabelecem relações com o modo de produção dominante sem que, $a$ priori, elas assumam um caráter capitalista. A contratação eventual ou regular de assalariados pelas unidades familiares ou sua inserção em circuitos mercantis, seja pela venda da força de trabalho (via atividades não-agrícolas), seja pela venda de produtos agrícolas, não autoriza a categorização compulsória como capitalistas.

De certo modo, o amplo apoio obtido por essa perspectiva, a partir das indicações de autores ligados à Sociologia da Agricultura, permite dizer que há muitas concordâncias em torno desse aporte, sobretudo no que se refere à identificação do cenário social e econômico em que transcorrem as transformações do capitalismo contemporâneo. Há consenso, por exemplo, no diagnóstico geral acerca da crise do fordismo e da validade de suas explicações sobre as novas formas de regulação social e econômica da estrutura agrária, fortemente marcadas pela consolidação do sistema agroalimentar internacional e pela mercantilização crescente tanto das relações de produção, como 
das dimensões que Marsden enquadra na esfera do "consumo não-produtivo", como a paisagem rural, o clima, o ambiente natural etc.

No entanto, em relação às avaliações sobre a pluriatividade e sobre a emergência de novas formas de regulação do trabalho no meio rural, a adesão da perspectiva analítica aqui proposta às idéias defendidas pelos autores da Sociologia da Agricultura é parcial. Embora se aceite que as transformações do mercado de trabalho sejam conseqüências de um padrão pós-fordista em gestação, não se considera que a pluriatividade seja um fenômeno decorrente apenas de processos sociais e econômicos externos às unidades familiares, sem implicar qualquer tipo de (re)ação dos sujeitos afetados. Seria um equívoco afirmar que os agricultores familiares sejam meros coadjuvantes ou simples bearers of structures (suportes das estruturas), e que não contribuam, em alguma medida, para a afirmação da pluriatividade.

As avaliações da Sociologia da Agricultura parecem satisfatórias em relação aos aspectos macrosociológicos pelos quais se explica o recurso dos agricultores às atividades não-agrícolas. Contudo, elas têm pouco a dizer sobre as motivações dos indivíduos, sobre como tomam suas decisões de dispêndio ou investimento, ou mesmo sobre os projetos que orientam suas estratégias de busca de alternativas materiais à sua reprodução social. Ou seja, para entender a complexidade das relações sociais engendradas nesse processo, é preciso estudar a pluriatividade a partir do modo como é exercida pelos próprios agricultores familiares. Dessa forma, é preciso adentrar no ambiente intrafamiliar para conhecer melhor os mecanismos pelos quais uma família se torna pluriativa e de que modo ela exerce essa pluriatividade.

\section{A familia pluriativa: em busca de uma unidade de análise}

A partir dos elementos teóricos até aqui apresentados torna-se necessário fixar uma unidade de observação pertinente ao estudo da pluriatividade e da agricultura familiar. A unidade de análise serve para se fixar o "campo de observação" dos fe- nômenos empíricos e funciona como um recurso heurístico e metodológico que recorta o objeto da análise sociológica. Nesse sentido, adverte-se para o fato de que a abordagem empreendida aqui considera as famílias rurais unidades onde a presença da pluriatividade deve ser entendida como um ponto de partida para reflexão sobre o próprio funcionamento e as características da agricultura familiar. Portanto, a unidade que servirá de referência metodológica, e que deverá se constituir em locus privilegiado da observação sociológica, será a família rural e não as atividades não-agrícolas exercidas por alguns de seus membros. A família é entendida como um grupo social que compartilha um mesmo espaço (não necessariamente uma habitação comum) e possui em comum a propriedade de um pedaço de terra para cultivo agrícola. Está ligada por laços de parentesco e consangüinidade (filiação), podendo a ele pertencer, eventualmente, outros membros não consangüíneos (adoção). É no âmbito familiar que se discute e se organiza a inserção produtiva, laboral, social e moral de seus integrantes, e é em função desse referencial que se estabelecem as estratégias individuais e coletivas que visam a garantir a reprodução do grupo. Embora seu objetivo seja a reprodução material, cultural e moral do grupo, não há, para tanto, caminho predeterminado ou estratégias definidas ex ante.

Para operacionalizar a utilização da família como unidade analítica sugere-se sua separação, para fins heurísticos, em unidades familiares de produção e grupos domésticos (Neves, 1995, 1997; Carneiro, 1998). Esta separação consiste em um ato abstrato e tem por finalidade entender melhor as relações sociais que ocorrem nas duas dimensões fundamentais da vida - o trabalho e a sociabilidade. Não se trata de uma cisão, mas de uma operação racional por meio da qual o pesquisador estu$\mathrm{da}$ as situações em que as famílias ou os indivíduos recorrem às atividades não-agrícolas e à pluriatividade como estratégias para viabilizar seus interesses pessoais ou coletivos - geralmente, elevação da renda ou busca por trabalhos menos penosos (Schneider, 1999b, p. 125).

Conforme também haviam sugerido Fuller (1984) e Barthez (1982, 1987), a separação da 
unidade familiar em unidade de produção e grupo doméstico funciona como um recurso metodológico que permite ir além das necessárias, mas insuficientes, medidas da quantidade de tempo de trabalho e do valor das rendas obtidas fora da propriedade como critérios definidores de uma unidade familiar pluriativa. Definir a pluriatividade pela obtenção de rendas externas à unidade ou a utilização de tempo de trabalho em outras atividades que não a agricultura implica em um reducionismo conceitual que desconsidera as outras causas que podem estar na origem da decisão de um indivíduo ou de uma família em optar por uma dada estratégia. Conhecer essas causas é absolutamente fundamental para que se possa evidenciar as diferentes formas de alocação do trabalho no interior da propriedade que, provavelmente, variam entre unidades exclusivamente agrícolas e as que combinam a agricultura com outros tipos de atividade. Isso permite compreender as variações da pluriatividade em situações onde as propriedades, seus sistemas produtivos e o contexto social e econômico são semelhantes. Ademais, a separação entre unidade de produção e grupo doméstico também permite utilizar na análise a variação da composição demográfica da família como elemento importante à compreensão das distintas formas que assume a pluriatividade, bem como os efeitos diferenciados que decorrem da inserção do homem ou da mulher em atividades não-agrícolas.

Segundo Neves, esse recurso metodológico pode promover o estudo da dinâmica da organização familiar sem necessariamente determinar $e x$ ante os projetos familiares ou os resultados das pressões do ambiente social e econômico. A distinção entre unidade familiar e unidade de produção permitiria, assim, evidenciar a coexistência de múltiplos projetos e arranjos entre os membros da família, pois "[...] as unidades de produção são arranjos contingenciais. Não são essências. São formas de conexão, de disjunção e de conjunção. São sistemas de procedimentos e de estratégias e não uma estrutura dada à qual aos indivíduos só cabe a própria modelação" (Neves, 1995, p. 34).

Além dessa "manobra heurística", que pretende dar um enfoque multidimensional à unida- de de análise - família rural -, considera-se necessário tecer um último comentário sobre a utilização do conceito de estratégia, que muitas vezes aparece adjetivado como estratégia de reprodução. Ele não é apenas o elo entre as unidades familiares e o ambiente externo, mas também a ligação que parece superar a dicotomia sociológica acerca do problema da relação estrutura/agente ou processos micro versus macro.

A utilização do conceito de estratégia deve levar em consideração os marcos teóricos e conceituais sobre as unidades familiares e sua relação com o contexto socioeconômico específico. Do ponto de vista substantivo, as estratégias podem ser interpretadas como o resultado das escolhas, das opções e das decisões dos indivíduos em relação à família e, inversamente, da família em relação aos indivíduos (Marini e Pieroni, 1987). É preciso ponderar, contudo, que essas estratégias ocorrem nos limites de determinados condicionantes sociais, culturais, econômicos e até mesmo espaciais, que exercem pressão sobre as unidades familiares. Portanto, a tomada de decisão e as opções, sejam quais forem, possuem um referencial que, na prática, se materializa por meio das relações sociais, econômicas e culturais estabelecidas entre os indivíduos. Assim, embora se tratem de estratégias conscientes e racionais, essa consciência é mediatizada por uma racionalidade informada pela realidade que tanto é a expressão das relações materiais presentes como daquelas herdadas e transmitidas culturalmente. Desse modo, as estratégias não são causais ou teleológicas, mas, o resultado da ação humana ante as contingências objetivas.

\section{Considerações finais}

Não está entre os objetivos deste trabalho o estabelecimento de aspectos conclusivos a respeito do tema. A apresentação de uma revisão da literatura, seguida por uma discussão sobre as melhores possibilidades analíticas e conceituais para o estudo da pluriatividade, não deve ser encarada como receita ou indicações infalíveis. Além disso, o que procurou-se demonstrar é que também no 
terreno dos estudos rurais e agrários recentes aflora uma discussão interessante sobre o próprio caráter da teoria social. De um lado, os autores parecem hesitar em abrir um diálogo mais franco com perspectivas teóricas e epistemológicas rivais, preferindo implementar o intercâmbio de conceitos e noções. Esse tipo de iniciativa parece interessante, pois indica uma postura de reconhecimento da capacidade heurística que certos conceitos possuem, independentemente das matrizes teóricas a que pertencem. De outro, observa-se a preocupação com os referenciais teóricos em segundo plano. Essas perspectivas, embora muito difundidas na literatura, por opção deliberada do autor foram pouco exploradas neste trabalho.

Assim, quando se realiza um balanço das teorias utilizadas pelos cientistas para estudar temáticas rurais e agrárias, percebe-se que também estas passam por ajustes e desafios semelhantes aos que afetam a teoria social contemporânea como um todo, a saber, interesses voltados ao diálogo multi e interdisciplinar, de um lado, e a tendência à fragmentação e ao pluralismo, de outro. Nesse caso, caberia especular sobre a opção que poderá vir a se tornar hegemônica no contexto das ciências sociais brasileiras, exercício que foge aos propósitos e mesmo à competência deste trabalho.

Em relação ao debate sobre a agricultura familiar, resta acrescentar que as sugestões de conceitos e de enfoques apresentadas não se prendem às unidades agrícolas. Ou seja, quando se propõe estudar as formas familiares de organização do trabalho e da produção não se está imaginando que elas estejam restritas ao setor agrícola e ao espaço rural, pois existem várias outras atividades em que se pode observar essa configuração. O mesmo pode ser afirmado em relação à pluriatividade, que se apresenta como um fenômeno social relativamente novo e desconhecido no espaço rural, embora suas características há muito estejam presentes nas diversas formas de trabalho (precário ou não) exercidas no âmbito urbano-industrial, pois, em essência, trata-se da combinação de mais de uma atividade ocupacional por pessoas que pertencem a uma mesma família. Curiosamente, as famílias urbanas nunca foram chamadas de pluriativas pelo fato de haver em sua unidade domiciliar pessoas com múltiplas inserções profissionais. Nesse sentido, o debate sobre a pluriatividade ganha uma nova frente de discussão, que leva à reflexão sobre o processo de homogeneização social, econômica, cultural e simbólica das famílias rurais e urbanas ou das famílias em geral.

\section{NOTAS}

1 O trabalho de Cavazzani e Fuller (1982) é pioneiro na tentativa de procurar uma alternativa ao conceito de agricultura em tempo-parcial.

2 Mais adiante será retomada a definição de pluriatividade tal como é concebida nas pesquisas realizadas no escopo do Arkleton Trust, com o qual o embasamento teórico e metodológico deste artigo encontra grande afinidade.

3 Para os historiadores franceses, "amplamente inserida no espaço rural, a pluriatividade é uma característica permanente e estrutural dos campos franceses. Trabalho a domicílio, em atelier ou em fábricas, os chefes de família praticam a alternância entre o setor agrícola e os setores secundário ou terciário, os membros auxiliares da família exercem uma preciosa atividade de apoio onde todos os tipos de situações existem e coexistem. Portanto, a pluriatividade não se constituiu em um campo de estudos específicos para os historiadores" (Garrier e Hubscher, 1988). Para mais informações, consultar também Hubscher, Farcy e Mesliand, todos publicados no livro ARF (1984).

4 Conforme enfatizou Kautsky "[...] a indústria constitui a mola não apenas de sua própria evolução, mas ainda da evolução agrícola [...]. A grande indústria passa agora a dominar. A agricultura deve obedecer às suas ordens, adaptar-se às suas exigências"(1980, pp. 317 e 319).

5 Portanto, trata-se de uma perspectiva analítica informada por um referencial que hoje se denominaria de microsociológico, o qual requer mediações teórico-conceituais para poder ser aplicado à análise de fenômenos desconhecido pelos camponeses russos.

6 A utilização dessa expressão parece ser uma clara tentativa de demarcar um campo de oposição à tradição da Rural Sociology (sociologia rural) norteamericana, de inspiração estrutural-funcionalista.

7 Para uma análise mais detalhada dessas vertentes teóricas, consultar Schneider (1999b, capítulo 2). 
8 O pós-produtivismo é definido por Marsden como "uma fase que é parcialmente apoiada pela habilidade inerente dos agricultores de se integrar a agentes e setores de atividades não-agrícolas" (1995, p. 294).

9 Em outro trabalho, Marsden define a mercantilização em termos muito semelhantes a Long, Van der Ploeg, Curtin e Box (1986), ao afirmar que "[...] o processo de mercantilização, em linhas gerais, envolve a extensão da forma mercadoria a novas esferas de atividade ou, o que é mais usual nas economias avançadas, a superposição de novos tipos de relações mercantis" (Marsden, 1989, p. 314).

10 Na verdade, há uma literatura expressiva que trata desse processo, especialmente no âmbito da chamada "geografia econômica". Para não citar vários autores estrangeiros, indica-se as revisões de Schneider (1999a) e Raud (1999).

11 Essa abordagem também encontra seguidores no Brasil. Para mais detalhes, consultar Graziano da Silva, Balsadi e Del Grossi (1997).

12 Essa pesquisa pode ser considerada o estudo mais completo e aprofundado sobre a pluriatividade e as atividades rurais não-agrícolas nos países europeus. Ela abrangeu 24 regiões de 12 países, sendo que nove são membros da Comunidade Européia e três não. O estudo foi realizado entre 1987 e 1991 e envolveu a aplicação de um questionário-base em 1987 e, outro, em 1992, com uma amostra estratificada de trezentos estabelecimentos em cada região (totalizando 6.600 propriedades em 22 áreas). Foram também realizados estudos de caso aprofundados (chamados de "estudo de contexto"), entre 1988 e 1989, com mais setenta estabelecimentos de cada região (Arkleton Trust Project, 1992).

13 Em Schneider (1999) pode-se encontrar argumentos mais detalhados acerca desses elementos conceituais.

14 Quando um pesquisador analisa uma situação concreta, tendo como variável a forma de uso da força de trabalho, e chega a conclusão de que a caracterização de determinadas unidades se dá pelo seu caráter familiar ou capitalista, ele está, no limite, reproduzindo uma fórmula dualista de pensamento que pouco auxilia a explicação sociológica. Para o aprofundamento dessa questão, consultar o excelente artigo de Neves (1995).

15 Há uma vasta bibliografia que discute as particularidades ou os obstáculos naturais para a realização da produção capitalista na agricultura. As posições mais interessantes sobre esse tema foram desenvolvidas por Mann (1990, cap. 1) e Abromovay (1992, p. 247).
16 Essa perspectiva de análise está de acordo com as idéias de Friedmann (1978a, 1978b) e Carneiro (1996b).

\section{BIBLIOGRAFIA}

ABRAMOVAY, R. (1992), Paradigmas do capitalismo agrário em questão. São Paulo, Anpocs/Unicamp/Hucitec.

ANJOS, F. S. (1995), Agricultura familiar em transformação: os colonos-operários de Massaranduba (SC). Pelotas, UFPEL.

ANJOS, F. S. (2001) "Pluriatividade e ruralidade: enigmas e falsos dilemas". Estudos Sociedade e Agricultura, 17: 54-81, out., Rio de Janeiro.

ARKLETON TRUST. (1992), Adaptation des ménages agricoles en Europe Occidentale: rapport final du Programme de Recherche sur les Structures et la Pluriactivité des Ménages Agricoles. Luxembuourg, Comission Européenne.

ASSOCIATION des Ruralistes Français. (1984), La pluriativité dans les familles agricoles. Paris, ARF Éditions.

BARTHEZ, A. (1987), "Familia, actividad y pluriatividad en la agricultura", in Arklenton Research, Cambio rural en Europa, Coloquio de Montpellier, Madrid, Ministerio de Agricultura, Pesca y Alimentación, pp. 161-179.

(1982), Famille, travail et agriculture. Paris, Economica.

BRADLEY, T. (1984), "Segmentation in local labor markets", in T. Bradley e P. Lowe (eds.), Locality and rurality: economy and society in rural regions, Norwich, Geo Books, pp. 310-331.

BRUN, A. \& FULLER, A. (1991), Farm family pluriactivity in Western Europe. United Kingdow, The Arkleton Research.

BUTTEL, F. H. \& LARSON, O. W. (1982), "Political implications of multiple jobholding in 
U.S. Agriculture: an exploratory analysis". Rural Sociology, 47 (2): 272-294, Kansas.

BUTTEL, F. H.; LARSON, O. F. \& GILLESPIE, G. W. (1990), The rural sociology of agriculture (under the auspices of the rural sociological society). Nova York, Greenwood Press.

BUTTEL, F. H. \& NEWBY, H. (1980), The rural sociology of advanced societies: critical perspectives. Londres, Croon Helm.

CAMPANHOLA, C. \& GRAZIANO DA SILVA, J. (orgs.). (2000), O novo rural brasileiro. Jaguariúna (SP), Embrapa Meio Ambiente, 4 vols.

CARNEIRO, M. J. (1998), Camponeses, agricultores e pluriatividade. Rio de Janeiro, Contracapa.

(1996a), "Pluriatividade no campo: o caso francês". Revista Brasileira de Ciências Sociais, 11 (32): 89-105, São Paulo, out.

. (1996b), "Pluriactivité agricole: l'héterogénéité cachée". Cabiers d'Economie et Sociologie Rurales, 38: 7-36, Paris.

CAVAZZANI, A. \& FULlER, A. (1982), "International perspectives on part-time farming: a review". Geojournal, Grait Briatin, 6 (4): 383-390.

CHAYANOV, A. V. (1974), La organización de la unidad económica campesina. Buenos Aires, Nueva Visión.

FRIEDMANN, H. (1978a), "Simple commodity production and wage labor in the American plains". Journal of Peasant Studies, 6 (1): 71-100, Londres.

. (1978b), "World market, State and family farm: social bases of household production in the era of wage labor". Comparative Studies in Society and History, 20 (4): 545-586, Cambridge.

FULLER, A. M. (1983), "Part-time farming and the farm family: a note for future re- search". Sociologia Ruralis, 23 (1): 5-9, Netherlands.

(1984), "Part-time farming: the enigmas and the realities", in H. Schwarzweller, Research in rural sociology and development, Connecticut, Jai Press.

(1987), "Introducción", in Arkleton Research, Cambio Rural en Europa, Coloquio de Montpellier, Madrid, Ministerio de Agricultura, Pesca y Alimentación.

. (1990), "From part-time farming to pluriativity: a decade of change in rural Europe". Journal of Rural Studies, 6 (4): 361-373, Londres.

FULLER, A. M. \& BRUN, A. (1988), "Social-economic aspects of pluriactivity in Western Europe", in Rural Change in Europe, Arkleton Research, second review meeting, Waldkirchen, 18-21 set., pp. 147-167.

GARRIER, G. \& HUBSCHER, R. (orgs.). (1988), Entre faucilles et marteaux. Lyon, Presses Universitaires de Lyon/Editions de la Maison des Sciences del l'Homme.

GOODMAN, D.; SORJ, B. \& WILKINSON, J. (1990), Da lavoura às biotecnologias. Rio de Janeiro, Campus.

GRAZIANO DA SILVA, J. (1999), O novo rural brasileiro. Campinas, Unicamp, Instituto de Economia (coleção Pesquisas, 1).

GRAZIANO DA SILVA, J.; BALSADI, O. V. \& DEL GROSSI, M. E. (1997), "O emprego rural e a mercantilização do espaço agrário". São Paulo em Perspectiva, 11 (2): 50-64, São Paulo.

KAGEYAMA, A. (1998), "Pluriatividade e ruralidade: aspectos metodológicos". Economia Aplicada, 2 (3): 515-551, jul./set. São Paulo.

KAUTSKY, K. (1980), A questão agrária. Portugal, Proposta.

LONG, N.; VAN DER PLOEG, J. D.; CURTIN, C. \& BOX (1986), The commoditization deba- 
te: labor process, strategy and social network. Netherlands, Agricultural University of Wagening.

MANN, S. (1990), Agrarian capitalism in theory and practice. Chapel Hill/Londres, The University of North Carolina Press.

MARINI, M. \& PIERONI, O. (1987), "Relación entre la Familia y el Entorno Social. Tipología de las Familias Agrícolas en una Zona Marginal (Calabria)", in Arkleton Research, Cambio Rural en Europa, Coloquio de Montpellier, Madrid, Ministerio de Agricultura, Pesca y Alimentación, pp. 205-247.

MARSDEN, T. (1989), "Restructuring rurality: from order to disorder in agrarian political economy". Sociologia Ruralis, 29 (3/4): 312-317, Netherlands.

(1990), "Towards the political economy of pluriactivity". Journal of Rural Studies, 6 (4): 375-382, Londres.

. (1991), "Theoretical issues in the continuity of petty commodity production", in S. Wathmore; P. Lowe e T. Marsden (eds.), Rural enterprise: shifting perspectives on small-scale production, Londres, David Fulton Publishers.

(1992), "Exploring a rural sociology for the fordist transition: incorporating social relations into economic restructuring”. Sociologia Ruralis, 32 (2/3): 209230, Netherlands.

(1995), "Beyond agriculture? Regulating the new rural spaces". Journal of Rural Studies, 11 (3): 285-296, Londres.

MARSDEN, T.; WHATMORE, S.; MUNTON, R. \& LITTLE (1986), "Towards a political economy of capitalist agriculture: a British perspective". International Journal of Urban and Regional Research, 4: 498-521.

MARSDEN, T. et al. (1987), "Uneven development and the restructuring process in British agriculture: a preliminary exploration".
Journal of Rural Studies, 3 (4): 297-303, Londres.

MARSDEN, T. \& FLYNN, A. (1993), "Servicing the city: contested transitions in rural realm". Journal of Rural Studies, 9 (3): 201-204, Londres.

MARSDEN, T.; MUNTON, R. \& WARD, N. (1992), "Incorporating social trajectories into uneven agrarian development: farm businesses in upland and lowland Britain”. Sociologia Ruralis, 32 (4): 408430, Netherlands.

MUNTON, R. \& MARSDEN, T. (1991), "Dualism or diversity in family farming? Patterns of occupancy changes in British agriculture”. Geoforum, 22 (1): 105-117, Londres.

NEVES, D. (1995), "Agricultura familiar: questões metodológicas". Revista Reforma Agrária, 25: 21-37, maio/dez., Campinas.

(1997), "Agricultura familiar e mercado de trabalho". Revista Estudos Sociedade e Agricultura, 8: 7-25, abr, Rio de Janeiro.

NEWBY, H. (1987), "Presentación: la familia y la explotación agraria", in Arkleton Research, Cambio rural en Europa, Coloquio de Montpellier, Madrid, Ministerio de Agricultura, Pesca y Alimentación, pp. 155-161.

RAUD, C. (1999), Indústria, território e meio ambiente no Brasil: perspectivas da industrialização descentralizada a partir da análise da experiência catarinense. Florianópolis, Editora da FURB/Editora da UFSC.

SCHNEIDER, S. (1994), "O desenvolvimento agrícola e as transformações da estrutura agrária nos países do capitalismo avançado: a pluriatividade". Revista Reforma Agrária, 24 (3): 106-132, set./dez., Campinas.

(1995), "As transformações recentes da agricultura familiar no Rio Grande do Sul: o caso da agricultura em tempo-parcial". 
Ensaios FEE, 16 (1): 105-119, Porto Alegre. . (1997), "Da crise da sociologia rural à emergência da sociologia da agricultura". Cadernos de Ciência e Tecnologia, 14 (2): 225-238, Brasília.

. (1999a), Agricultura familiar e industrialização: pluriatividade e descentralização industrial no Rio Grande do Sul. Porto Alegre, Editora da UFRGS. . (1999b), Agricultura familiar e pluriatividade. Tese de doutorado, Porto Alegre, UFRGS, Programa de Pós-Graduação em Sociologia.

VAN DER PLOEG, J. D. (1992), "El proceso de trabajo agrícola y la mercantilización", in $\mathrm{E}$. S. Guzman (ed.), Ecologia, campesinado $y$ historia, Espanha, Las Ediciones de la Piqueta.

. (1993), "Rural sociology and the new agrarian question: a perspective from the Netherlands". Sociologia Ruralis, 33 (2): 240-260, Netherlands. 
TEORIA SOCIAL, AGRICULTURA FAMILIAR E PLURIATIVIDADE

Sérgio Schneider

\section{Palavras-chave}

Teoria social contemporânea; Agricultura familiar; Trabalho rural; Pluriatividade; Sociologia rural.

Este artigo procura apresentar um referencial de análise que permita entender a pluriatividade como um estratégia de reprodução social e econômica das famílias rurais. O tema central trata a agricultura familiar e a pluriatividade do ponto de vista teórico e conceitual. Situa-se o contexto em que aparece o estudo da agricultura familiar e da pluriatividade no Brasil e discute-se a origem e a evolução do debate sobre a pluriatividade, uma situação eminentemente relacionada à realidade dos países desenvolvidos. Situamse, ainda, as análises sobre a pluriatividade no contexto das tradições teóricas clássicas dos estudos agrários, mostrando como esse fenômeno já fora objeto de preocupação de outros autores. Analisa-se, em seguida, a pluriatividade no âmbito das principais abordagens analíticas contemporâneas da teoria social e indica-se qual o referencial teórico que parece adequado ao seu estudo. Por fim, é indicada uma perspectiva metodológica para o estudo da pluriatividade em unidades familiares.

\section{SOCIAL THEORY, FAMILY FAR- MING AND PLURIACTIVITY}

Sérgio Schneider

\section{Keywords}

Contemporary social theory; Familiar agriculture; Rural work; Pluriactivity; Rural sociology.

This paper aims at presenting an analytical reference that allows understanding pluriactivity as a strategy for social and economic reproduction for rural families. In the introduction, we present the context in which the study of family farming and pluriactivity emerges in Brazil. In the first section, we discuss the origin and evolution of the debate about pluriactivity, a situation mainly related to the reality in developed countries. In the second section, we try to position the analysis of pluriactivity in the context of the theoretical traditions that are classical in agrarian studies, showing how this phenomenon has already been object of concern for others authors. In the third section, we aim to position pluriactivity in the main contemporaneous analytical approaches of the social theory and indicate which one seems to be adequate for the study. In the fourth section, we discuss the central theme of this paper, which is the relationship between family farming and pluriactivity from a theoretical and conceptual point of view. In the fifth section, we indicate a methodological perspective to study pluriactivity in family units.
THÉORIE SOCIALE, AGRICULTURE FAMILIALE ET PLURIACTIVITÉ

Sérgio Schneider

\section{Mots-clés}

Théorie sociale contemporaine; Agriculture familiale; Paysan; Pluriactivité; Sociologie rurale.

Cet article présente un référentiel d'analyse permettant de comprendre la pluriactivité en tant que stratégie de reproduction sociale et économique des familles rurales. Dans l'introduction, l'auteur situe le contexte dans lequel émerge l'étude de l'agriculture familiale et de la pluriactivité au Brésil. La première partie aborde l'origine et l'évolution du débat sur la pluriactivité, une situation éminemment liée à la réalité des pays développés. Dans la seconde partie, l'auteur cherche à situer les analyses sur la pluriactivité dans le contexte des traditions théoriques classiques des études agraires, en montrant comment ce phénomène a déjà été l'objet d'études par d'autres auteurs. Dans la troisième partie, l'auteur situe la pluriactivité dans les principales approches analytiques contemporaines de la théorie sociale et indique quel est le référentiel théorique qui correspond le mieux à son étude. La quatrième partie aborde le thème central de l'article, qui se réfère à la relation de l'agriculture familiale et de la pluriactivité du point de vue théorique et conceptuel. La cinquième et dernière partie, est indiquée une perspective méthodologique pour l'étude de la pluriactivité dans les unités familiales. 